\section{MALAUEME PERPUSTIMAM SEMOLAL}

Buku manajemen perpustakaan sekolah ini membahas perlunya perpustakaan sekolah dikelola dengan baik sesuai dengan prinsipprinsip manajemen. Hal ini dimaksutkan untuk menghasilkan dan mempertahankan kualitas kinerja, kualitas produk, dan seluruh proses kegiatan perpustakaan sekolah agar sesuai dengan kebutuhan sekolah, kebutuhan guru, dan kebutuhan siswa. Untuk itu keberadaan perpustakaan sekolah perlu memperoleh perhatian dari pihak manajemen sekolah. Penguatan kelembagaan perpustakaan sekolah dalam struktur makro organisasi sekolah perlu mendapat perhatian. Selain itu keberadaan perpustakaan sekolah perlu ditunjang dengan aspek-aspek bersifat teknis yang sangat dibutuhkan oleh perpustakaan sekolah seperti tenaga, dana, serta sarana, prasarana dan teknologi, dan tidak kalah pentingnya dari semua itu adalah adanya manajemen perpustakaan sekolah yang diaplikasikan di lingkungan perpustakaan sekolah.

Dengan sentuhan manajemen, tujuan dan fungsi perpustakaan dapat tercapai dengan baik sesuai dengan tujuan yang telah ditentukan. Perpustakaan sekolah perlu dikelola dengan baik sesuai dengan prinsip-prinsip manajemen, agar mempunyai kekuatan sebagai daya ungkit terhadap peningkatan kualitas pembelajaran di sekolah dan sekaligus juga sebagai daya ungkit terhadap kualitas lulusan peserta didik. Buku ajar ini membahas secara sederhana tentang pengertian umum perpustakaan, sejarah perpustakaan, definisi perpustakaan sekolah, manfaat dan tujuan perpustakaan sekolah dan seluruh proses pengelolaan perpustakaan sekolah serta pada pengembangan budaya dan penanaman minat baca siswa di sekolah.
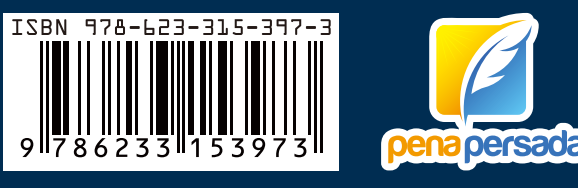

Rini Setyaningsih, M.Pd.



\section{MANAJEMEN} PERPUSTAKAAR SEKOLAH 


\section{MANAJEMEN PERPUSTAKAAN SEKOLAH}

RINI SETYANINGSIH, M.Pd.

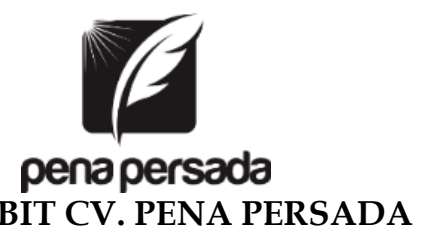




\title{
MANAJEMEN PERPUSTAKAAN SEKOLAH
}

\author{
Penulis: \\ Rini Setyaningsih, M.Pd. \\ ISBN: 978-623-315-397-3 \\ Design Cover: \\ Retnani Nur Briliant \\ Layout: \\ Nisa Falahia \\ Penerbit CV. Pena Persada \\ Redaksi: \\ Jl. Gerilya No. 292 Purwokerto Selatan, Kab. Banyumas \\ Jawa Tengah \\ Email: penerbit.penapersada@gmail.com \\ Website: penapersada.com Phone: (0281) 7771388 \\ Anggota IKAPI \\ All right reserved \\ Cetakan pertama: 2021
}

Hak Cipta dilindungi oleh undang-undang. Dilarang memperbanyak karya tulis ini dalam bentuk apapun tanpa izin penerbit 


\section{KATA PENGANTAR}

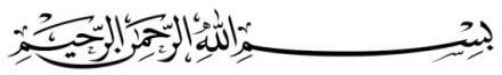

Penulis memanjatkan Puji dan Syukur kepada Allah SWT, karena atas limpahan rahmat dan hidayah-Nyalah, penulis dapat menyelesaikan buku ajar dengan judul "MANAJEMEN PERPUSTAKAAN SEKOLAH". Penulis berharap buku ajar ini dapat membawa manfaat bagi penulis sendiri dalam mengembangkan keilmuanya, dan para mahasiswa yang mengambil mata kuliah manajemen perpustakaan sebagai alat untuk lebih memudahkan dalam memahami mata kuliah tersebut, serta beberapa rekan dosen yang sama-sama mengampu mata kuliah Manajemen Perpustakaan sebagai tambahan refensi.

Perpustakaan merupakan jantung dari sekolah guna meningkatkan pembelajaran dan kemajuan pendidikan. Manajemen Perpustakaan yang baik adalah kunci sukses tercapainya tujuan Pendidikan dan salah satu faktor untuk dapat meningkatkan mutu Pendidikan. Melalui perpustakaan sekolah para siswa, guru bahkan semua warga sekolah dapat mengunjunginya untuk menambah wawasan dan menambah ilmu pengetahuan yang mungkin sebelumnya belum pernah didapatkan.

Buku ajar yang sederhana dan praktis ini disusun untuk memudahkan para mahasiswa dalam memahami bagaimana mengelola sebuah perpustakaan sekolah dengan baik. Agar tujuan dan fungsi sebuah perpustakaan sekolah dapat tercapai. Dengan tercapainya tujuan dan fungsi sebuah perpustakaan sekolah maka besar kemungkinan akan tercapai pula tujuan Pendidikan. Penulis menyadari akan adanya kekurangan pada pembahasan dalam buku ajar ini, oleh karenanya penulis akan terima dengan senang hati atas kritik dan saran yang membangan demi penyempurnaannya buku ajar ini.

Pada kesempatan ini penulis menyampaikan terima kasih kepada semua pihak yang telah membantu penulis dalam menyusun buku ajar ini. Akhirnya, semoga buku ajar ini bermanfaat bagi semua pihak yang berminat terhadap pembinaan 
dan pengelolaan perpustakaan sekolah, bagi para Dosen pengampu mata kuliah manajemen perpustakaan, bagi para kepala sekolah, guru, pustakawan dan terkhusus bagi para mahasiswa yang sedang mengambil mata kuliah manajemen perpustakaan.

Pekanbaru, April 2021

Penulis 


\section{DAFTAR ISI}

KATA PENGANTAR .................................................................

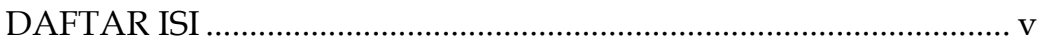

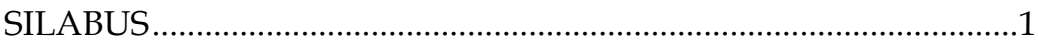

BAB I PENGANTAR UMUM PERPUSTAKAAN ..............................

A. Defenisi/Pengertian Perpustakaan ....................................... 8

B. Fungsi Perpustakaan ......................................................

C. Manfaat perpustakaan.........................................................11

D. Macam-macam Perpustakaan ………..............................11

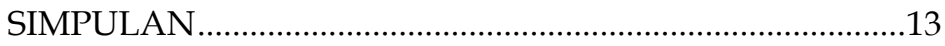

BAB II SEJARAH PERPUSTAKAAN ............................................14

A. Sejarah perpustakaan di Indonesia ......................................14

B. Sejarah perpustakaan di Dunia ..........................................19

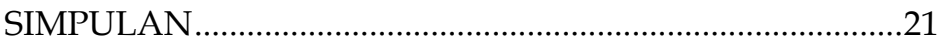

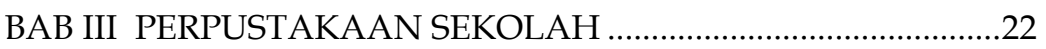

A. Pengertian Perpustakaan Sekolah......................................22

B. Dasar Hukum Perpustakaan ................................................24

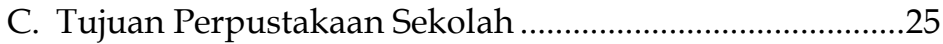

D. Manfaat Perpustakaan Sekolah ..........................................26

E. Bentuk Organisasi dan Uraian Tugas Perpustakaan.......28

1. Perpustakaan sekolah sebagai unit kerja......................28

2. Proses Pembentukan Perpustakaan ..............................29

3. Struktur Organisasi Perpustakaan ................................29

4. Anggaran Perpustakaan ................................................... 31

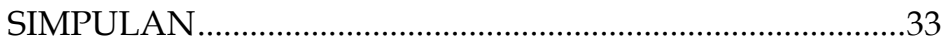

BAB IV ADMINISTRASI DAN ORGANISASI

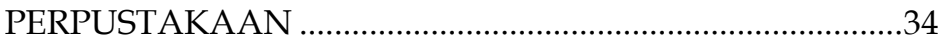

A. Pengertian Administrasi Perpustakaan .................................34

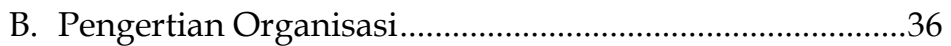

C. Struktur Organisasi Perpustakaan...........................................

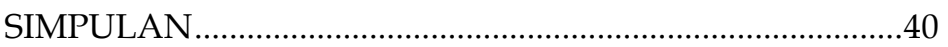

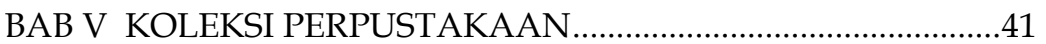

A. Pengertian Koleksi Perpustakaan ........................................41

B. Jenis Koleksi Perpustakaan ................................................. 


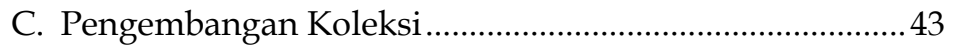

D. Pengadaan Koleksi................................................................ 45

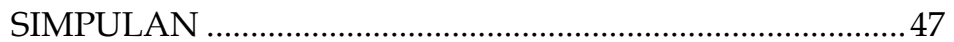

BAB VI PENGOLAHAN BAHAN-BAHAN PUSTAKA.................. 48

A. Definisi Pengolahan Bahan-Bahan Pustaka .......................4 48

B. Tujuan dan Fungsi/Manfaat Pengolahan Bahan

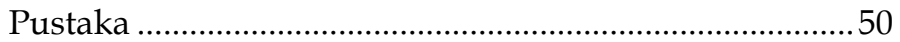

C. Langkah - Langkah Pengolahan Bahan Pustaka..............51

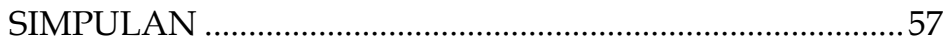

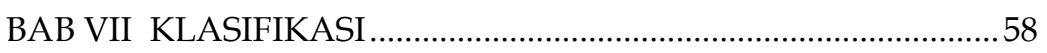

A. Pengertian Klasifikasi perpustakaan...................................58

B. Prinsip-prinsip dalam Pengklafikasian...............................59

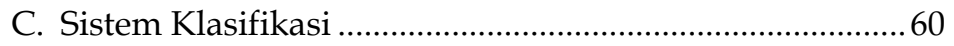

D. Prosedur Klasifikasi Perpustakaan.........................................63

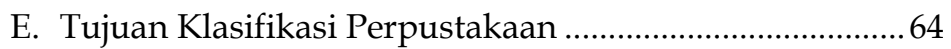

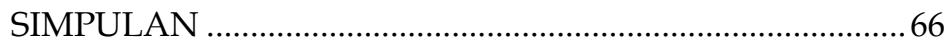

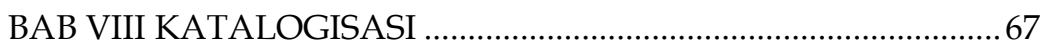

A. Pengertian Katalog dan Katalogisasi Perpustakaan ........67

B. Tujuan dan Fungsi Katalog Perpustakaan .......................69

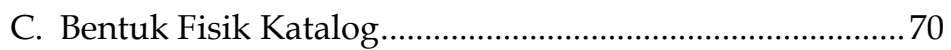

D. Cara Penyusunan Katalog ................................................ 72

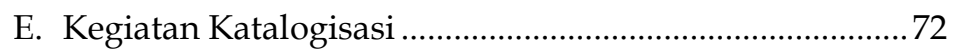

F. Cara Membuat Kartu Katalog ............................................... 73

G. Kelebihan OPAC dari Katalog Kartu atau Manual ..........74

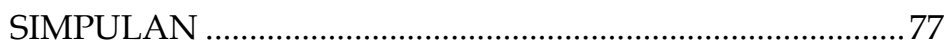

BAB IX PELAYANAN PERPUSTAKAAN ……............................... 78

A. Jenis Pelayanan Pembaca .................................................. 78

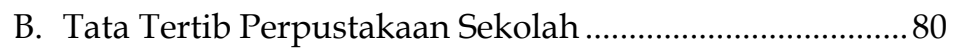

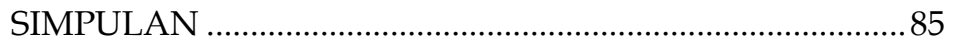

BAB X PEMELIHARAAN DAN PERAWATAN BAHAN

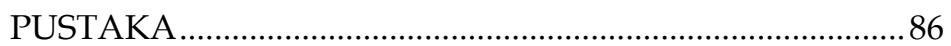

A. Pengertian Pemeliharaan Bahan Pustaka ...........................86

B. Tujuan Pemeliharaan Bahan-Bahan Pustaka ..................... 87

C. Fungsi pemeliharaan bahan-bahan pustaka ...................... 87

D. Manfaat Pemeliharaan Bahan Pustaka .............................. 89

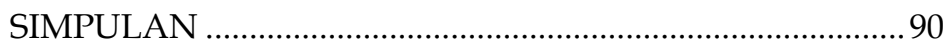


BAB XI PERAN DAN PEMBINAAN PETUGAS

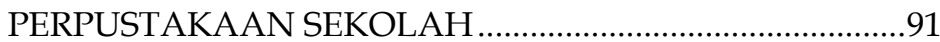

A. Peran Pustakawan...............................................................91

B. Pembinaan petugas perpustakaan sekolah .......................95

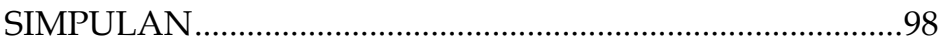

BAB XII PEMBENTUKAN BUDAYA BACA DI SEKOLAH ..........99

A. Pengertian Budaya baca di Sekolah...................................100

B. Peran Kepala Sekolah dalam Membentuk Budaya

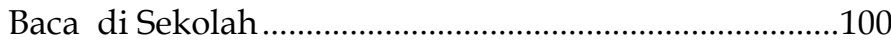

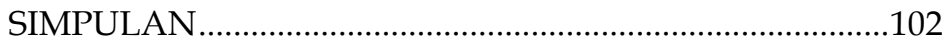

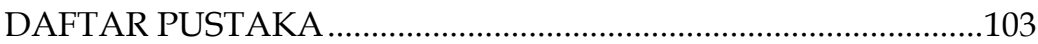

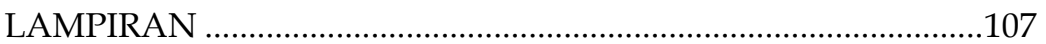

1. Salinan Peraturan Kepala Perpustakaan Nasional Republik Indonesia Nomor 10 Tahun 2017 Tentang Standar Nasional Perpustakaan Sekolah Dasar/ Madrasah Ibtidaiyah

2. Salinan Peraturan Kepala Perpustakaan Nasional Republik Indonesia Nomor 11 Tahun 2017 Tentang Standar Nasional Perpustakaan Sekolah Menengah Pertama/ Madrasah Tsanawiyah

3. Salinan Peraturan Kepala Perpustakaan Nasional Republik Indonesia Nomor 12 Tahun 2017 Tentang Standar Nasional Perpustakaan Sekolah Menengah Atas/ Madrasah Aliyah ....137 
MANAJEMEN PERPUSTAKAAN SEKOLAH 


\section{SILABUS}

\section{INFORMASI UMUM}

Fakultas

Jurusan

: Tarbiyah dan Keguruan

: MPI/ AP

Nama Mata Kuliah

Jumlah SKS

: Manajemen Perpustakaan

: 2 SKS

: PMK 1459

Kode Mata Kuliah

: Keilmuan dan Keterampilan Khusus

\section{DESKRIPSI MATA KULIAH}

Materi yang dibahas dalam mata kuliah ini berkenaan dengan: Pengantar umum perpustakaan, Pengertian Perpustakaan Sekolah, Sejarah Perpustakaan, Administrasi dan Organisasi Perpustakaan, Koleksi Perpustakaan, Klasifikasi, Katalogisasi, Pelayanan Perpustakaan, Pemeliharaan dan Perawatan Bahan Perpustakaan, peran dan pembinaan petugas perpustakaan sekolah, Peran Kepala Sekolah dalam manajemen perpustakaan, Pembinaan dan pengembangan budaya baca di sekolah.

\section{KOMPETENSI YANG DIHARAPKAN}

Setelah mengikuti mata kuliah ini mahasiswa MPI memiliki kompetensi sebagai berikut:

a. Mengetahui dan memahami hal-hal dalam manajemen perpustakaan sekolah yaitu, Pengertian Perpustakaan Sekolah, Sejarah Perpustakaan, Administrasi dan Organisasi Perpustakaan, Koleksi Perpustakaan, Klasifikasi, Katalogisasi, Pelayanan Perpustakaan, Pemeliharaan dan Perawatan Bahan Perpustakaan 
b. Mengetahui dan memahami peran, tugas dan pembinaan petugas perpustakaan sekolah

c. Mengetahui dan memahami Peran Kepala Sekolah dalam manajemen perpustakaan, Pembinaan dan pengembangan budaya baca di sekolah.

\section{SISTEM PENILAIAN}

Penilaian dilakukan dengan mempertimbangkan hal-hal sebagai berikut:
a. Ujian akhir semester
$: 30 \%$
b. Ujian tengah semester
$: 30 \%$
c. Tugas kelompok dan presentasi
$: 15 \%$
d. Tugas Individu/Partisipasi/keaktifan/kehadiran : 25\%

5. MATERI PERKULIAHAN

\begin{tabular}{|c|c|c|c|}
\hline Pertemuan & $\begin{array}{c}\text { Kemampuan akhir yang } \\
\text { diharapkan }\end{array}$ & Indikator & Pokok Pembahasan \\
\hline 1 dan 2 & $\begin{array}{l}\text { Mahasiswa mampu } \\
\text { memahami pengantar umum } \\
\text { perpustakaan }\end{array}$ & $\begin{array}{l}\text { Mahasiswa mampu } \\
\text { menjelaskan: } \\
\text { 1. Pengertian perpustakaan } \\
\text { 2. Fungsi perpustakaan } \\
\text { 3. Manfaat perpustakaan } \\
\text { secara umum }\end{array}$ & $\begin{array}{l}\text { 1. Pengertian perpustakaan } \\
\text { 2. Fungsi perpustakaan } \\
\text { 3. Manfaat perpustakaan } \\
\text { secara umum } \\
\text { 4. Macam-macam } \\
\text { perpustakaan }\end{array}$ \\
\hline
\end{tabular}




\begin{tabular}{|c|c|c|c|}
\hline & & $\begin{array}{l}\text { 4. Macam-macam } \\
\text { perpustakaan }\end{array}$ & \\
\hline 3 & $\begin{array}{l}\text { Mahasiswa } \\
\text { memahami } \\
\text { Perpustakaan }\end{array}$ & $\begin{array}{l}\text { Mahasiswa mampu } \\
\text { menjelaskan: } \\
\text { 1. Sejarah Perpustakaan di } \\
\text { Indonesia } \\
\text { 2. Sejarah Perpustakaan Dunia }\end{array}$ & $\begin{array}{l}\text { 1. Sejarah Perpustakaan di } \\
\text { Indonesia } \\
\text { 2. Sejarah Perpustakaan } \\
\text { Dunia }\end{array}$ \\
\hline 4 & $\begin{array}{lr}\text { Mahasiswa } & \text { mampu } \\
\text { memahami Konsep } & \text { dasar } \\
\text { perpustakaan sekolah } & \end{array}$ & $\begin{array}{l}\text { Mahasiswa } \\
\text { mejelaskan: } \\
\text { 1. Pengertian Perpustakaan } \\
\text { Sekolah } \\
\text { 2. Dasar Hukum Perpustakaan } \\
\text { 3. Tujuan } \quad \text { Perpustakaan } \\
\text { Sekolah } \\
\text { 4. Manfaat } \quad \text { Perpustakaan } \\
\text { Sekolah } \\
\text { 5. Bentuk Organisasi dan } \\
\text { Uraian Tugas Perpustakaan } \\
\text { Sekolah }\end{array}$ & $\begin{array}{l}\text { 1. Pengertian Perpustakaan } \\
\text { Sekolah } \\
\text { 2. Dasar } \\
\text { Perpustakaan } \\
\text { 3. Tujuan Pukum } \\
\text { Sekolah } \\
\text { 4. Manfaat Perpustakaan } \\
\text { Sekolah } \\
\text { 5. Bentuk Organisasi dan } \\
\text { Uraian Tugas } \\
\text { Perpustakaan Sekolah }\end{array}$ \\
\hline
\end{tabular}




\begin{tabular}{|c|c|c|c|}
\hline 5 & $\begin{array}{l}\text { Mahasiswa mampu } \\
\text { memahami Administrasi dan } \\
\text { Organisasi Perpustakaan }\end{array}$ & $\begin{array}{l}\text { Mahasiswa mampu } \\
\text { menjelaskan: } \\
\text { 1. Pengertian Administrasi } \\
\text { 2. Pengertian Organisasi } \\
\text { 3. Struktur Organisasi } \\
\text { Perpustakaan }\end{array}$ & $\begin{array}{l}\text { 1. Pengertian Administrasi } \\
\text { 2. Pengertian Organisasi } \\
\text { 3. Struktur Organisasi } \\
\text { Perpustakaan }\end{array}$ \\
\hline 6 & $\begin{array}{l}\text { Mahasiswa } \\
\text { memahami } \\
\text { Perpustakaan }\end{array}$ & $\begin{array}{l}\text { Mahasiswa mampu } \\
\text { menjelaskan: } \\
\text { 1. Pengertian Koleksi } \\
\text { Perpustakaan } \\
\text { 2. Jenis Koleksi Perpustakaan } \\
\text { 3. Pengembangan Koleksi } \\
\text { 4. Pengadaan Koleksi } \\
\text { 5. Koleksi dan Pengolahan } \\
\text { Bahan Pustaka }\end{array}$ & $\begin{array}{l}\text { 1. Pengertian Koleksi } \\
\text { Perpustakaan } \\
\text { 2. Jenis Koleksi Perpustakaan } \\
\text { 3. Pengembangan Koleksi } \\
\text { 4. Pengadaan Koleksi } \\
\text { 5. Koleksi dan Pengolahan } \\
\text { Bahan Pustaka }\end{array}$ \\
\hline 7 & $\begin{array}{l}\text { Mahasiswa } \quad \text { mampu } \\
\text { memahami Klasifikasi bahan } \\
\text { pustaka }\end{array}$ & 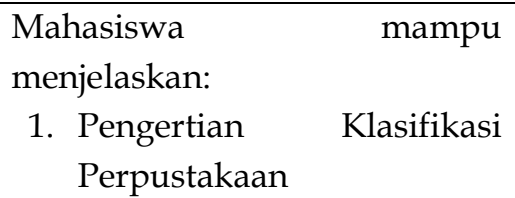 & $\begin{array}{l}\text { 1. Pengertian Klasifikasi } \\
\text { Perpustakaan } \\
\text { 2. Prinsip-Prinsip } \\
\text { Pengklasifikasian }\end{array}$ \\
\hline
\end{tabular}




\begin{tabular}{|c|c|c|c|}
\hline & & $\begin{array}{ll}\text { 2. Prinsip-Prinsip } \\
\text { Pengklasifikasian } \\
\text { 3. Sistem Klasifikasi } \\
\text { 4. Macam-Macam Klasifikasi } \\
\text { 5. Prosedur Klasifikasi } \\
\text { Perpustakaan }\end{array}$ & $\begin{array}{ll}\text { 3. } & \text { Sistem Klasifikasi } \\
\text { 4. } & \text { Macam-Macam Klasifikasi } \\
\text { 5. Prosedur Klasifikasi } & \\
& \text { Perpustakaan }\end{array}$ \\
\hline 8 & UJIAN & TENGAH & SEMESTER \\
\hline 9 & $\begin{array}{l}\text { Mahasiswa mampu } \\
\text { memahami pengolahan } \\
\text { bahan-bahan pustaka }\end{array}$ & $\begin{array}{l}\text { Mahasiswa mampu } \\
\text { menjelaskan: } \\
\text { 1. Definisi pengolahan bahan } \\
\text { pustaka } \\
\text { 2. Tujuan dan fungsi } \\
\text { pengelolaan bahan pustaka } \\
\text { 3. Langkah-langkah } \\
\text { pengolahan bahan pustaka }\end{array}$ & $\begin{array}{l}\text { 1. Definisi pengolahan bahan } \\
\text { pustaka } \\
\text { 2. Tujuan dan fungsi } \\
\text { pengelolaan bahan pustaka } \\
\text { 3. Langkah-langkah } \\
\text { pengolahan bahan pustaka }\end{array}$ \\
\hline 10 & $\begin{array}{l}\text { Mahasiswa mampu } \\
\text { memahami Katalogisasi }\end{array}$ & $\begin{array}{l}\text { Mahasiswa mampu } \\
\text { menjelaskan: } \\
\text { 1. Pengertian Katalogisasi } \\
\text { 2. Macam-Macam Katalogisasi } \\
\text { 3. Tujuan Katalogisasi }\end{array}$ & $\begin{array}{l}\text { 1. Pengertian Katalogisasi } \\
\text { 2. Macam-Macam } \\
\text { Katalogisasi } \\
\text { 3. Tujuan Katalogisasi } \\
\text { 4. Fungsi Katalogisasi }\end{array}$ \\
\hline
\end{tabular}




\begin{tabular}{|c|c|c|c|}
\hline & & $\begin{array}{l}\text { 4. Fungsi Katalogisasi } \\
\text { 5. Prosedur Pengkatalogisasi }\end{array}$ & 5. Prosedur Pengkatalogisasi \\
\hline 11 & $\begin{array}{l}\text { Mahasiswa } \\
\text { memahami } \\
\text { Perpustakaan }\end{array}$ & $\begin{array}{ll}\text { Mahasiswa } & \text { mampu } \\
\text { menjelaskan: } & \\
\text { 1. Pengertian } & \text { Pelayanan } \\
& \text { Perpustakaan } \\
\text { 2. Jenis } & \\
& \text { Perpustakaan } \\
\text { 3. Tata tertib perpustakaan } \\
\text { sekolah }\end{array}$ & $\begin{array}{l}\text { 1. Pengertian Pelayanan } \\
\text { Perpustakaan } \\
\text { 2. Jenis Layanan } \\
\text { Perpustakaan } \\
\text { 3. Tata tertib perpustakaan } \\
\text { sekolah }\end{array}$ \\
\hline 12 & $\begin{array}{l}\text { Mahasiswa mampu } \\
\text { memahami pemeliharaan } \\
\text { bahan perpustakaan }\end{array}$ & $\begin{array}{l}\text { Mahasiswa mampu } \\
\text { menjelaskan: } \\
\text { 1. Pengertian pemeliharaan } \\
\text { bahan pustaka } \\
\text { 2. Tujuan Pemeliharaan } \\
\text { 3. Fungsi pemeliharaan } \\
\text { 4. } \text { Manfaat pemeliharaan }\end{array}$ & $\begin{array}{l}\text { 1. Pengertian pemeliharaan } \\
\text { bahan pustaka } \\
\text { 2. Tujuan Pemeliharaan } \\
\text { 3. Fungsi pemeliharaan } \\
\text { 4. Manfaat pemeliharaan }\end{array}$ \\
\hline 13 & $\begin{array}{rr}\text { mampu } \\
\text { peran } \begin{array}{r}\text { dan } \\
\text { petugas }\end{array}\end{array}$ & $\begin{array}{l}\text { Mahasiswa mampu } \\
\text { menjelaskan: } \\
\text { 1. Peran pustakawan }\end{array}$ & $\begin{array}{l}\text { 1. Peran pustakawan } \\
\text { 2. Pembinaan petugas } \\
\text { perpustakaan sekolah }\end{array}$ \\
\hline
\end{tabular}




\begin{tabular}{|c|c|c|c|}
\hline & perpustakaan sekolah & $\begin{array}{l}\text { 2. Pembinaan petugas } \\
\text { perpustakaan sekolah }\end{array}$ & \\
\hline 14 dan 15 & $\begin{array}{l}\text { Mahasiswa mampu } \\
\text { memahami pembentukan } \\
\text { budaya baca di sekolah }\end{array}$ & $\begin{array}{l}\text { Mahasiswa mampu } \\
\text { menjelaskan: } \\
\text { 1. Pengertian budaya baca di } \\
\text { sekolah } \\
\text { 2. Peran kepala sekolah } \\
\text { dalam membentuk budaya } \\
\text { baca di sekolah }\end{array}$ & $\begin{array}{l}\text { 1. Pengertian budaya baca di } \\
\text { sekolah } \\
\text { 2. Peran kepala sekolah } \\
\text { dalam membentuk budaya } \\
\text { baca di sekolah }\end{array}$ \\
\hline 16 & UJIAN & AKHIR & SEMESTER \\
\hline
\end{tabular}




\section{BAB I \\ PENGANTAR UMUM PERPUSTAKAAN}

Perpustakaan merupakan sistem informasi yang di dalamnya terdapat aktivitas pengumpulan, pengolahan, pengawetan, pelestarian dan penyajian serta penyebaran informasi. Perpustakaan sebagaimana yang ada dan berkembang sekarang telah dipergunakan sebagai salah satu pusat informasi, sumber ilmu pengetahuan, penelitian, rekreasi, pelestarian khasanah budaya bangsa, serta memberikan berbagai layanan jasa lainnya. Selain itu menurut perpustakaan adalah sebuah ruangan, bagian sebuah gedung, ataupun gedung itu sendiri yang digunakan untuk menyimpan buku dan terbitan lainnya menurut tata susunan tertentu untuk digunakan pembaca, bukan untuk dijual.

Sebagian besar masyarakat beranggapan bahwa perpustakaan merupakan tempat tumpukan buku tanpa mengetahui pasti ciri dan fungsi perpustakaan. Ada beberapa ciri yang perlu diketahui oleh masyarakat diantaranya adalah tersedianya koleksi, sarana prasarana, pustakawan dan pengunjung serta adanya suatu unit kerja. Oleh karena itu, faktorfaktor tersebut dapat mempengaruhi tingkat perkembangan perpustakaan, berdasarkan jumlah pengunjung yang datang ke perpustakaan tersebut. Kemajuan perpustakaan sekolah sebagai salah satu tolak ukur keberhasilan prestasi belajar karena perpustakaan sebagai penyedia informasi, khususnya bagi para siswa dalam memenuhi kebutuhan ilmu pengatahuannya.

\section{A. Defenisi/Pengertian Perpustakaan}

Dalam bahasa Indonesia istilah "perpustakaan" dibentuk dari kata dasar pustaka ditambah awalan "per" dan akhiran "an". Menurut Kamus Umum Bahasa Indonesia perpustakaan diartikan sebagai "kumpulan bukubuku". Dalam bahasa Inggris disebut "library yang berarti perpustakaan. Dalam bahasa Arab disebut "alMaktabah" yang berarti tempat 
menyimpan buku-buku. Sedangkan menurut istilah "Perpustakaan merupakan kumpulan bahan tercetak dan non tercetak dan atau sumber informasi dalam komputer yang tersusun secara sistematis untuk kepentingan pemakai. ${ }^{1}$

Menurut Sutarno NS, "Perpustakaan adalah suatu ruangan, bagian dari gedung/bangunan, atau gedung itu sendiri, yang berisi bukubuku koleksi, yang disusun dan diatur sedemekian rupa sehingga mudah dicari dan dipergunakan apabila sewaktu-waktu diperlukan untuk pembaca. Adjat Sakri menjelaskan, bahwa perpustakaan adalah lembaga yang menghimpun pustaka dan menyediakan sarana bagi orang untuk memanfaatkan koleksi pustaka tersebut. Larasati Milburga, dkk mendefinisikan bahwa perpustakaan adalah suatu unit kerja yang berupa tempat menyimpan koleksi bahan pustaka yang diatur secara sistematis dengan cara tertentu untuk digunakan secara berkesinambungan oleh pemakainya sebagai sumber informasi.

Dari beberapa pengertian di atas dapat ditarik suatu kesimpulan pengertian perpustakaan sesecara umum adalah suatu unit kerja yang berupa tempat mengumpulkan, menyimpan dan memelihara koleksi pustaka baik buku-buku ataupun bacaan lainnya yang diatur, diorganisasikan dan diadministrasikan dengan cara tertentu untuk memberi kemudahan dan digunakan secara kontinu oleh pemakainya sebagai informasi.

\section{B. Fungsi Perpustakaan}

Perpustakaan sekolah merupakan bagian penting dari program penyelengaraan pendidikan tingkat sekolah yang memiliki fungsi untuk mendukung penyelenggaraan perpustakaan sekolah. Menurut Pawit M. Yusuf perpustakaan sekolah memiliki empat fungsi umum yaitu $:^{2}$

1 Basuki \& Sulistyo, Pengantar Ilmu Perpustakaan, (Jakarta: Gramedia Pustaka Utama,1991) hlm. 3

2 Darmono. Manajemen dan Tata Perpustakaan Sekolah (Jakarta: Gramedia Widiasarana Indonesia,2001) hlm. 4 
1. Fungsi Edukatif yaitu secara keseluruhan segala fasilitas, sarana dan prasaranan perpustakaan sekolah, terutama koleksi dapat membantu murid dalam proses belajar.

2. Fungsi Informatif dari perpustakaan sekolah adalah mengupayakan penyediaan koleksi yang bersifat memberi tahu akan hal-hal yang berhubungan dengan kepentingan guru dan murid.

3. Fungsi Kreasi, bukan merupakan fungsi utama, namun sangat penting kedudukannya dalam upaya peningkatan intelektual dan inspirasi.

4. Fungsi Riset, membuat koleksi yang ada di perpustakaan sekolah menjadi bahan riset atau penelitian sederhana. Kemudian, secara umum fungsi dari perpustakaan adalah sebagai berikut:

a. Fungsi informasi, yaitu perpustakaan menyediakan berbagai informasi yang meliputi bahan cetak, terekam, maupun koleksi lainnya agar dapat memenuhi kebutuhan masyarakat sekolah.

b. Fungsi pendidikan. Perpustakaan sebagai sarana untuk meningkatkan mutu pendidikan dan menerapkan tujuan pendidikan

c. Fungsi kebudayaan. Perpustakaan sebagai sarana peningkatan mutu kehidupan dan menumbuhkan budaya membaca.

d. Fungsi rekreasi. Perpustakaan sebagai sarana untuk pemanfaatan waktu lenggang dengan bacaan yang bersifat rekreatif dan hiburan yang positif

e. Fungsi penelitian. Perpustakaan memiliki koleksi-koleksi untuk menunjang kegiatan penelitian.

f. Fungsi deposit. Perpustakaan berkewajiban menyimpan dan melestarikan karya-karya, baik cetak maupun noncetak, yang diterbitkan di wilayah indonesia. 


\section{Manfaat perpustakaan}

Menurut Cella manfaat dari keberadaan perpustakaan sekolah adalah merangsang minat baca baik pada guru dan siswa, merupakan sumber literatur yang paling dekat, perpustakaan sebagai pusat sumber informasi dan sumber pembelajaran menulis. Selain itu manfaat dari perpustakaan diantaranya sebagai berikut: ${ }^{3}$

1. Mempercepat penguasaan teknik membaca

2. Melatih perserta belajar pada arah tanggungjawab ilmiah dan teknologi

3. Membantu guru untuk menemukan sumber-sumber pengajaran.

4. Membantu seluruh elemen pendidikan dalam mengikuti perkembangan ilmu pengetahuan.

5. Membantu perserta didik dalam kelancaran tugas-tugas belajarnya.

6. Menanamkan kebiasaan belajar mandiri oleh peserta didik tanpa bimbingan guru secara langsung.

7. Menimbulkan kecintaan peserta didik terhadap kegiatan pengetahuan, baik yang telah dipelajari maupun yang belum dipelajari.

\section{Macam-macam Perpustakaan}

Ditinjau dari skala kegiatan dan jangkauan penggunaannya, serta jenis koleksi yang ada didalamnya, perpustakaan di bedakan jenisnya sebagai berikut :

1. Perpustakaan Nasional

Perpustakaan nasional adalah perpustakaan yang dikelola pemerintah pada tingkat nasional dan berfungsi sebagai perpustakaan nasional

2. Perpustakaan Umum

Perpustakaan umum adalah yang dibiayai dari dana umum, baik sebagian atau seluruhnya, terbuka untuk masyarakat umum tanpa membeda-bedakan usia, jenis

${ }^{3}$ Suherlan, dkk. Perpustakaan. (Bandung: PT Puri Pustaka, 2008) hlm. 6 